\title{
Studi Potensi Lansekap Sejarah untuk Pengembangan Wisata Sejarah di Kota Singaraja
}

\author{
SUGENG RIYANTO1*, I MADE SUKEWIJAYA', LURY SEVITA YUSIANA²
}

1. Program Studi Agroekoteknologi, Fakultas Pertanian, Universitas Udayana

Jl. PB. Sudirman, Denpasar, 80232, Bali

2. Program Studi Arsitektur Pertamanan, Fakultas Pertanian, Universitas Udayana

Jl. PB. Sudirman, Denpasar, 80232, Bali

*E-mail: sugeng_riyanto09@yahoo.com

\section{ABSTRACT \\ Study of The Potential Landscape History for The Development of Historical Tourism in Singaraja City}

A development of region to improve as a tourism destination will give some positive effects especially for economic sector. Singaraja city is part of northern Bali which has potential of history tourism which need to improve, that is because of the variety of history belong of there, from Buleleng Dinasty till the colonialism era in Republic of Indonesia. The improving of history tourism in Singaraja City hope will give some positive effects especially for civilians who living around. This research has done from Mei 2013 till December 2014 at administration territorial of Singaraja City. As the result of the research, over all the landscape history of Singaraja City has completed all the criteria of history tourism, although there is still need to do some treatments to develop the enchantments of the tourism destination. Based on the result of the research, it is a recommendation is a city tour system which concept learnt by travelling.

Keywords: landscape, historical landscape, historical tourism

\section{Pendahuluan}

Pengembangan suatu daerah menjadi tujuan wisata akan memberikan berbagai dampak positif terutama dampak ekonomi. Menurut Muljadi dan Warman (2014) bahwa dampak positif pariwisata terhadap pembangunan ekonomi antara lain; memberikan pekerjaan dan penghasilan untuk masyarakat setempat, menghasilkan devisa bagi negara, sebagai pendorong bagi pembangunan ekonomi lainnya, serta membiayai pembangunan prasarana yang mempunyai manfaat ganda.

Kota Singaraja berada di wilayah Bali Utara. Kota Singaraja memiliki potensi wisata untuk dapat dikembangkan. Potensi wisata tersebut didasarkan pada sejarah Kota Singaraja. Kota Singaraja merupakan bukti fisik yang menjadi saksi terhadap kejayaan Kerajaan Buleleng, penguasaan pemerintah Hindia Belanda di Indonesia, hingga 
perjuangan rakyat Indonesia dalam merebut kemerdekaan. Berbagai obyek peninggalan sejarah masih dapat ditemukan di Kota Singaraja.

Pengembangan lansekap sejarah sebagai tujuan wisata merupakan salah satu bentuk pelestarian dan perlindungan terhadap peninggalan sejarah, serta pengenalan dan penghargaan terhadap sejarah bangsa. Untuk mengembangkan lansekap sejarah sebagai tujuan wisata, maka perlu dilakukan studi untuk melihat potensi wisata pada lansekap sejarah Kota Singaraja. Berdasarkan latar belakang yang diuraikan di atas, maka dapat dirumuskan masalah sebagai berikut antara lain: 1). Bagaimana potensi lansekap sejarah sebagai obyek pengembangan wisata sejarah Kota Singaraja?, 2). Bagaimana upaya peningkatan lansekap sejarah sebagai daya tarik wisata sejarah Kota Singaraja?, 3). Bagaimana bentuk pengembangan wisata sejarah Kota Singaraja berdasarkan potensi lansekap sejarahnya?.

Lebih lanjut penelitian ini dilakukan dengan tujuan antara lain untuk: 1) Mengetahui potensi lansekap sejarah untuk dapat dikembangkan menjadi wisata sejarah Kota Singaraja, 2) Menganalisis potensi lansekap sejarah untuk dapat dikembangkan menjadi wisata sejarah Kota Singaraja, 3) Merekomendasikan wisata sejarah Kota Singaraja berdasarkan potensi lansekap sejarah.

\section{Metode}

\subsection{Waktu dan Lokasi Penelitian}

Lokasi studi dilakukan dalam lingkup administrasi Kota Singaraja. Pemilihan Kota Singaraja sebagai lokasi studi didasarkan atas pertimbangan bahwa Kota Singaraja merupakan lokasi utama dari rangkaian peristiwa sejarah sehingga banyak lansekap sejarah yang terpusat di Kota Singaraja. Studi potensi dilaksanakan Bulan Mei 2013 hingga Bulan Desember 2013. Tahap inventarisasi data dilakukan mulai Bulan Mei 2013 hingga Bulan Agustus 2013. Tahap analisis hingga hasil dilakukan pada Bulan AgustusDesember 2013.

\subsection{Alat dan Bahan}

Alat yang digunakan pada studi ini meliputi kamera digital dan sistem komputerisasi. Kamera digital digunakan untuk mengetahui fakta di lapangan. Sedangkan komputerisasi untuk penulisan hasil penelitian di lapangan.

\subsection{Data Penelitian}

Jenis data yang digunakan pada penelitian ini bersumber dari data primer dan data sekunder. Data primer berupa pengumpulan data berdasarkan hasil observasi langsung di lokasi dan wawancara yang melibatkan pemerintah serta masyarakat setempat. Sedangkan data sekunder diperoleh melalui studi kepustakaan yaitu pengumpulan data melalui sumber-sumber tertulis yang terdiri dari buku-buku teks, laporan ilmiah, arsip-arsip resmi, dan berbagai sumber lainnya. Pengolahan data dilakukan dengan cara melakukan transkripsi data yaitu mencatat seluruh data yang diperoleh melalui metode pengumpulan data, mereduksi data yaitu melakukan pemotongan data yang tidak relevan dengan obyek penelitian, mengklasifikasi data sesuai komponen yang diamati untuk setiap metode pengumpulan data, serta menganalisis data sesuai dengan tujuan analisis. 


\subsection{Kerangka Metode Penelitian}

Terdapat beberapa tahapan yang dilakukan pada studi potensi lansekap sejarah Kota Singaraja. Tahapan tersebut meliputi tahap inventarisasi, analisis, sintesis, serta tahap hasil. Tahapan-tahapan tersebut dapat dilihat dengan jelas pada Gambar 1.

Gambar 1. Bagan Kerangka Metode Penelitian

\section{Hasil dan Pembahasan}

\subsection{Kondisi Umum Kota Singaraja}

\subsubsection{Kondisi Geografis Kota Singaraja}

Kota Singaraja secara geografis terletak pada $8^{\circ} 3^{\prime} 40^{\prime \prime}-8^{\circ} 23^{\prime} 00^{\prime \prime}$ LS dan $114^{\circ} 25^{\prime} 55$ $115^{\circ} 27^{\prime 2} 2$ " BT. Topografi wilayah Kota Singaraja berada pada ketinggian antara 10-500 meter dari permukaan laut, morfologi lahan daratan yang memiliki sudut lereng $0-5 \%$ pada ketinggian 10-40 meter dan perbukitan dengan sudut lereng 5-30\% pada ketinggian 40- 
500 meter di atas permukaan laut. Memiliki luas wilayah 27,89 $\mathrm{km}^{2}$ dan termasuk dalam bagian administrasi dari Kabupaten Buleleng (Badan Pusat Statistik Kabupaten Buleleng, 2012).

\subsubsection{Kondisi Sosial dan Masyarakat Kota Singaraja}

Kota Singaraja pada tahun 2013 memiliki jumlah penduduk sebanyak 132,719 jiwa. Mayoritas penduduk Kota Singaraja memeluk agama Hindu yakni sebanyak 101,987 jiwa, sedangkan agama lain seperti Islam sebanyak 15,856 jiwa, Budha sebanyak 2,666 jiwa, Protestan sebanyak 1,089 jiwa dan Katolik sebanyak 1,047 jiwa (Badan Pusat Statistik Kabupaten Buleleng, 2012).

\subsubsection{Sejarah dan Perkembangan Kota Singaraja}

Terbentuknya Singaraja menjadi sebuah kota yakni diawali dengan berdirinya sebuah istana kerajaan yang dibangun oleh Raja Ki Gusti Ngurah Panji Sakti beserta rakyatnya setelah menaklukkan Kerajaan Belambangan pada tahun Candrasangkala Raja Manon Buta Tunggal (30 Maret 1604 M). Istana kerajaan tersebut adalah Puri Singaraja atau dikenal juga dengan nama Puri Buleleng. Pemilihan kata Singaraja merupakan bentuk apresiasi terhadap kepemimpinan Raja Ki Gusti Ngurah Panji Sakti yang gagah berani seperti Singa ketika berada di medan perang. Sedangkan kata Buleleng adalah pengertian terhadap istana yang dibangun diatas lahan tanaman jagung gembal. Pemerintahan Kerajaan Buleleng merupakan awal perkembangan Kota Singaraja. Berbagai aktivitas pada periode pemerintahan Kerajaan Buleleng terpusat di kawasan Catus Patha (perempatan agung). Pada periode ini pembangunan di bidang pertahanan dan ekonomi merupakan pembangunan yang paling menonjol sehingga berdampak terhadap persebaran masyarakat Kota Singaraja. Hingga saat ini Kota Singaraja dihuni oleh beberapa kelompok masyarakat non-lokal (etnis) pendatang seperti masyarakat Kampung Bugis yakni orang-orang suku Bajo yang dahulunya adalah pasukan armada laut kerajaan, masyarakat Kampung Arab, serta kelompok etnis tionghoa yang dahulunya sebagai pedagang.

Pada Tahun 1849 M pemerintah Hindia Belanda secara resmi menguasai Kota Singaraja. Dalam rangka memperkuat kekuasaannya, Kota Singaraja dikembangkan menjadi Kota Kolonial. Kota Singaraja dijadikan pusat aktivitas yang berhubungan dengan pemerintahan, ekonomi dan sosial budaya. Untuk menunjang tujuan tersebut maka dilakukan pembangunan dan perbaikan sarana dan prasarana publik seperti kantor pemerintahan, rumah-rumah pejabat, jembatan, jalan, serta pelabuhan. Terdapatnya pelabuhan yang dibangun oleh pemerintah Hindia Belanda membuat ekonomi Buleleng semakin membaik. Untuk memudahkan hubungan dengan masyarakat maka pemerintah Hindia Belanda membangun kembali pemerintahan lokal dengan cara mengangkat Raja dari keturunan pendiri Kerajaan Buleleng yang sekaligus sebagai asisten pemerintahan Hindia Belanda. Mulai tahun 1901 M pemerintah Hindia Belanda menerapkan ethisce politiek (politik beretika) sehingga pemerintahan di Buleleng lebih banyak dikendalikan oleh pejabat lokal seperti Patih, Sedahan Agung, para Punggawa, Perbekel dan Pemuka Masyarakat. Pembangunan prasarana dan sarana umum seperti jalan, pasar, penataan kawasan kantor pemerintahan, tempat ibadah dan pemukiman dikerjakan secara 
berkesinambungan. Pada tahun 1913 M pembangunan sekolah untuk rakyat dibangun serentak hingga ke desa-desa. Periode pemerintahan Hindia Belanda berakhir tahun 1946 M dan juga diikuti oleh berakhirnya masa pemerintahan Kerajaan Buleleng tahun 1950 M (Sentanu, 2013).

Periode kemerdekaan tahun 1945 M Kota Singaraja menjadi Ibu Kota Kepulauan Sunda Kecil yang dijabat oleh Mr. I Gusti Ketut Puja sebagai Gubernur. Kota Singaraja pada saat itu berada di bawah kekuasaan pemerintah Jepang masih berstatus sebagai Ibu Kota Sunda Kepulauan Kecil dan lbu Kota Provinsi Bali. Fisik kota pada masa pemerintahan Jepang berlangsung tidak mengalami banyak perubahan. Kota Singaraja sebagai Ibu Kota Provinsi Bali berakhir sejak dikeluarkan Keputusan Menteri Dalam Negeri No. Des.52/2/36-136 Tanggal 23 Juni 1960 yang menetapkan Kota Denpasar sebagai Ibu Kota Provinsi Bali (Dinas Kebudayaan dan Pariwisata, 2013).

\subsection{Lansekap Sejarah Kota Singaraja}

Berdasarkan hasil inventarisasi di lapangan terdapat beberapa lansekap sejarah Kota Singaraja. Lansekap sejarah tersebut antara lain; Perempatan Agung (Catus Patha), Masjid Kuno (Keramat), Masjid Agung Jami', Kampung Bugis, Kantor Bupati, Eks Pelabuhan Buleleng, kawasan Perdagangan, Klenteng Lin Gwan Kiong, Gedong Kirtya, Kawasan Jalan Ngurah Rai, SMPN 1 Singaraja, SMAN 1 Singaraja, serta SDN 1 dan 2 Paket Agung.

\subsubsection{Perempatan Agung (Catus Patha)}

Perempatan Agung (Catus Patha) terletak di perempatan Jl. Mayor Metra, Jl. Veteran, dan Jl. Gajah Mada. Catus Patha merupakan konsep tata ruang tradisional tentang perempatan jalan yang menjadi pusat pertumbuhan kota di Bali. Pembagian ruang pada perempatan agung terdiri dari pura sebagai tempat ibadah, puri sebagai pusat pemerintahan, pasar sebagai pusat ekonomi dan lapangan sebagai ruang terbuka hijau. Catus Patha Kota Singaraja telah ada sejak Kerajaan Buleleng mulai berdiri. Kawasan ini menjadi pusat aktivitas ekonomi dan pemerintahan ketika periode pemerintahan Kerajaan Buleleng berlangsung. Aksis Catus Patha saat ini merupakan perpindahan setelah kawasan sebelumnya mengalami kehancuran akibat bencana banjir bandang akibat pecahnya lereng bukit penyangga Danau Buyan pada tahun $1815 \mathrm{M}$.

\subsubsection{Masjid Kuno (Keramat)}

Masjid Kuno (Keramat) yang terletak di Jl. Hasanudin merupakan tempat ibadah umat Islam yang pertama di Kota Singaraja dan tergolong masjid tertua di Pulau Bali. Masjid Kuno dahulunya adalah bangunan terbengkalai yang telah ditutupi semak belukar yang ada di sekitar Sungai Buleleng. Masjid ini pertama kali ditemukan oleh orang Bajo Suku Bugis ketika membersihkan lahan semak belukar di pinggir Sungai Buleleng. Keberadaan Masjid Keramat sangat dikaitkan dengan masuknya ajaran agama Islam ke Bali oleh para santri atau murid walisongo pada masa pemerintahan Kerajaan Buleleng. Ini dibuktikan oleh bentuk dan arsitektur bangunan masjid yang menyerupai bangunanbangunan masjid di daerah demak. Bangunan ini akhirnya digunakan kembali sebagai tempat ibadah sejak masyarakat suku Bajo menetap di Kampung Kajanan. (Pengurus Masjid Kuno/Keramat, 2013). 


\subsubsection{Masjid Agung Jami'}

Masjid Agung Jami' merupakan tempat ibadah bagi umat Islam yang didirikan pada periode pemerintahan Kerajaan Buleleng. Masjid ini terletak di Jl. Imam Bonjol dan masuk ke dalam administrasi Kelurahan Kampung Bugis. Masjid Agung Jami' didirikan sebagai bentuk toleransi antar umat beragama ketika periode pemerintahan Kerajaan Buleleng berlangsung. Raja Anak Agung Ngurah Jelantik Polong (generasi ke-VI dari keturunan Ki Barak Panji Sakti) memberikan lahan yang lebih Representatif kepada umat Islam untuk mendirikan tempat ibadah karena kapasitas tempat ibadah sebelumnya (Masjid Kuno/Keramat) sudah tidak mencukupi lagi. Pembangunan masjid ini selesai pada tahun 1850 M (berdasarkan pintu gerbang masjid pemberian raja yang bertuliskan $1260 \mathrm{H}$ ). Masjid tersebut awalnya diberi nama Masjid Jami' yang artinya masjid yang dapat digunakan bersama-sama karena penggunaannya meliputi beberapa kampung di sekitarnya. Pada akhir tahun 1970-an nama Masjid Jami' berubah menjadi Masjid Agung Jami' oleh kerabat puri dan tokoh umat Islam sekitar untuk mengenang jasa kebaikan Raja Buleleng pada masa itu (Pengurus Masjid Agung Jami', 2013).

\subsubsection{Kampung Bugis}

Kampung Bugis yang berlokasi di Jl. Patimura merupakan kawasan pemukiman bagi masyarakat Suku Bugis. Pemukiman ini menjadi salah satu daerah administrasi wilayah Kota Singaraja yakni Kelurahan Kampung Bugis. Kampung Bugis mulai terbentuk ketika masyarakat Suku Bugis menetap di Kota Singaraja pada abad ke-17. Keberadaan masyarakat Suku Bugis di Kota Singaraja adalah sebagai armada laut bagi Kerajaan Buleleng. Perkembangan pemukiman masyarakat Bugis mengalami banyak perubahan mulai abad ke-18. Pemukiman ini tidak hanya dihuni oleh masyarakat Bugis asli, melainkan terdapat masyarakat etnis Arab yang juga menghuni pemukiman tersebut. Keberadaan masyarakat etnis Arab awalnya menawarkan dagangannya kepada masyarakat setempat, namun seiring perkembangan waktu orang-orang Arab menikah dengan penduduk lokal setempat hingga akhirnya menetap di kawasan ini (Susanti, 2014).

\subsubsection{Kantor Bupati Buleleng}

Kantor Bupati Buleleng yang terletak di Jl. Pahlawan ini dahulunya merupakan bangunan kantor Asisten Resident pada masa pemerintahan Hindia Belanda di Bali. Bangunan ini dibangun pada tahun $1849 \mathrm{M}$ setelah pemerintah Hindia Belanda resmi menguasai Kota Singaraja. Fungsi bangunan kantor tersebut oleh pemerintah Hindia Belanda adalah sebagai pusat pemerintahan di Kota Singaraja. Setelah periode kemerdekaan oleh pemerintah daerah bangunan ini digunakan sebagai Gedung Veteran dan Perguruan Tinggi.

\subsubsection{Eks Pelabuhan Buleleng}

Eks Pelabuhan Buleleng terletak di Jl. Erlangga dahulunya merupakan kawasan Pelabuhan Buleleng dan satu-satunya lansekap sejarah yang telah dikembangkan menjadi daya tarik wisata Kota Singaraja. Sejarah perkembangan tapak terbagi atas tiga periode berbeda yakni periode pemerintahan Kerajaan Buleleng, periode pemerintahan Hindia Belanda dan periode kemerdekaan. Pada periode pemerintahan Kerajaan Buleleng kawasan Pelabuhan Buleleng merupakan kawasan pemukiman bagi masyarakat suku 
Bugis. Pada periode pemerintahan Hindia Belanda kawasan Eks Pelabuhan Buleleng merupakan pintu gerbang utama Bali terutama untuk kegiatan distribusi barang. Untuk menunjang kegiatan tersebut, pemerintah Hindia Belanda membangun berbagai fasilitas seperti dermaga, gudang, terminal, kantor pabean dan jembatan. Sedangkan pada periode kemerdekaan kawasan ini merupakan medan pertempuran antara masyarakat Buleleng dan Tentara Nasional Indonesia melawan pasukan Belanda (Dinas Kebudayaan dan Pariwisata Kota Singaraja, 2013).

\subsubsection{Kawasan Perdagangan Kota Singaraja}

Kawasan perdagangan Kota Singaraja merupakan kawasan pertokoan di Kota Singaraja. Keberadaan kawasan perdagangan ini tidak terlepas dari padatnya aktivitas distribusi barang di Pelabuhan Buleleng ketika periode pemerintahan Hindia Belanda berlangsung. Deretan pertokoan yang sebagian besar milik etnis Tionghoa bermunculan dengan melakukan jual-beli barang distribusi pelabuhan. Perkembangan kawasan ini awalnya hanya terdapat di Jl. Erlangga dan hanya terdapat beberapa bangunan toko. Namun seiring perkembangan waktu, kawasan ini berkembang pesat hingga ke Jl. Imam Bonjol.

\subsubsection{Klenteng Lin Gwan Kiong}

Klenteng Lin Gwan Kiong merupakan bangunan tempat ibadah bagi umat Tionghoa. Klenteng Lin Gwan Kiong yang berada di Jl. Erlangga ini dibangun mulai tahun $1873 \mathrm{M}$ (terbaca pada prasasti di dalam Klenteng). Klenteng ini dibangun karena masyarakat etnis Tionghoa membutuhkan tempat untuk melakukan ibadah. Klenteng ini tidak hanya digunakan oleh masyarakat setempat, namun masyarakat lain dari luar Kota Singaraja (Pengurus Tempat Ibadah Tridharma, 2013).

\subsubsection{Gedong Kirtya}

Gedong Kirtya di Jl. Veteran ini adalah bangunan perpustakaan yang dibangun pada masa pemerintahan Hindia Belanda. Bangunan perpustakaan ini dahulunya merupakan sebuah yayasan yang dibangun untuk memperingati jasa-jasa dua orang cendikiawan Belanda yakni F. A. Lieffrinck dan Dr. H. N. Van Der Tuuk. Dua cendikiawan tersebut telah memplopori penyelidikan kebudayaan, adat istiadat dan bahasa di Bali. Nama Gedung peringatan tersebut dahulunya bernama Stichinhg Lieffrinck Van Der Tuuk. I Gusti Putu Jelantik (Raja Buleleng generasi X) menyarankan agar nama bangunan tersebut ditambahkan kata Kirtya dari bahasa sansekerta. Pada tanggal 2 Juni 1928 gedung ini resmi bernama Kirtya Lieffrinck-Van Der Tuuk dan resmi dibuka untuk umum pada tanggal 14 September 1928 oleh Gubernur Jendral Hindia Belanda (UPTD Gedong Kirtya, 2013).

\subsubsection{Kawasan Jl. Ngurah Rai}

Kawasan Jl. Ngurai Rai merupakan kawasan perumahan elit Pemerintah Hindia Belanda. Jalan Ngurai Rai dahulunya merupakan jalan yang dibangun oleh pemerintah Hindia Belanda sebagai penghubung antara kantor pemerintahan dengan kawasan ekonomi yakni kawasan perdagangan dan Pelabuhan Buleleng, sehingga untuk mempermudah pengawasan sekitar kawasan Jl. Ngurah Rai diperuntukkan sebagai rumah dinas elit pemerintah Hindia Belanda. 


\subsubsection{SMPN 1 Singaraja}

Sekolah Menengah Pertama Negeri (SMPN) 1 Singaraja berlokasi di Jl. Gajah Mada. SMPN 1 Singaraja dahulunya merupakan sebuah lembaga pendidikan kemiliteran dan gudang senjata pada masa Pemerintahan Hindia Belanda di Kota Singaraja. Fungsi bangunan sebagai lembaga pendidikan dan gudang senjata berakhir pada masa pendudukan Jepang di Bali. Bangunan ini selanjutnya oleh pemerintahan Jepang difungsikan sebagai sekolah umum yang diberi nama Chugakko. Fungsi bangunan sebagai sekolah umum bertahan hingga saat ini.

\subsubsection{SMAN 1 Singaraja}

SMAN 1 Singaraja yang berlokasi di Jl. Pramuka ini dahulunya merupakan bangunan Hogere Middelbare School (HMS). SMAN 1 Singaraja dibangun pada tanggal 1 November 1950 ini merupakan sekolah menengah atas yang pertama didirikan di Bali. Bangunan ini berdiri ketika pemerintah Hindia Belanda mulai menerapkan ethisce politiek yang ditandai dengan pembangunan pemerintahan lokal. Bangunan ini dahulunya digunakan sebagai tempat belajar bagi masyarakat Bali-Nusa Tenggara dengan tujuan untuk menciptakan pemimpin-pemimpin daerah.

\subsubsection{SDN 1 dan 2 Paket Agung}

SDN 1 dan 2 Paket Agung yang beralamat di Jl. Veteran merupakan bangunan sekolah Tweede Klasse School (sekolah pribumi kelas dua). Sekolah ini didirikan pada tahun 1875 ketika berlangsungnya periode pemerintahan Hindia Belanda. Di samping itu, sekolah ini juga dikaitkan dengan sejarah kelahiran Dr. Ir. Soekarno (presiden pertama RI). Sekolah ini merupakan tempat Raden Soekemi Sostrodihardjo (ayah Dr. Ir. Soekarno) mengajar. Raden Soekemi Sostrodihardjo bertemu Ni Nyoman Rai Srimben (ibu Dr. Ir. Soekarno) yang rumahnya berada di sekitar lingkungan sekolah ini. Dari perkawinan mereka kemudian lahir Soekarno (Sujaya, 2014).

\subsubsection{Rekomendasi Pengembangan Wisata Sejarah Kota Singaraja}

Berdasarkan hasil observasi di lapangan, Kota Singaraja memiliki ciri khas apabila dibandingkan dengan kota-kota lain di Bali. Ciri khas tersebut adalah bentuk atau perkembangan kota yang sangat didominasi oleh budaya Belanda. Bentukan tersebut terlihat hampir di seluruh kota termasuk Puri Buleleng (pusat pemerintahan Kerajaan Buleleng). Pengembangan wisata sejarah Kota Singaraja dapat diaplikasikan dengan menggunakan konsep learn by travelling dengan sistem city tour.

\section{Simpulan}

\subsection{Simpulan}

Berdasarkan hasil inventarisasi dan observasi lansekap sejarah Kota Singaraja, dapat disimpulkan bahwa Kota Singaraja merupakan kota bersejarah. Pertumbuhan dan perkembangan fisik Kota Singaraja sangat didominasi oleh budaya Belanda. Keseluruhan lansekap sejarah yang telah terinventarisasi telah memenuhi kriteria untuk dapat dikembangkan menjadi wisata sejarah Kota Singaraja, walaupun terdapat beberapa upaya yang perlu dilakukan untuk meningkatkan daya tarik wisata sejarah. Upaya peningkatan 
tersebut dapat dilakukan dengan mengatasi kendala pada lansekap sejarah maupun fasilitas penunjang wisata sejarah Kota Singaraja.

Lansekap sejarah Kota Singaraja dapat dikembangkan menjadi wisata sejarah menggunakan konsep learn by travelling dengan sistem city tour. Melalui konsep tersebut, diharapkan para wisatawan terutama masyarakat setempat dapat memahami sejarah Kota Singaraja, sehingga dapat melestarikan dan menghargai keberadaan peninggalan sejarah bangsa.

\subsection{Saran}

Pengembangan wisata sejarah Kota Singaraja perlu direncanakan dengan baik sehingga dapat memberikan manfaat terutama kepada masyarakat setempat. Untuk mewujudkan tujuan tersebut, maka perlu keterlibatan dan kerjasama seluruh pihak yang meliputi pemerintah daerah, investor, serta masyarakat sehingga dapat menetapkan kebijakan-kebijakan untuk menjaga kelestarian lansekap sejarah Kota Singaraja.

\section{Daftar Pustaka}

Badan Pusat Statistik Kabupaten Buleleng. 2012. Buleleng dalam Angka. Buleleng.

Dinas Kebudayaan dan Pariwisata Kabupaten Buleleng. 2013. Sejarah Perkembangan Pelabuhan Buleleng. Singaraja.

Muljadi, A. J. dan Warman, A. 2014. Kepariwisataan dan Perjalanan. Rajawali Pers, Jakarta.

Pengurus Masjid Agung Jami'. 2013. Sekilas Riwayat Singkat Masjid Agung Jami' Singaraja. Singaraja.

Pengurus Masjid Kuno. 2013. Sejarah Singkat Masjid Kuno/Keramat Singaraja Kabupaten Buleleng. Singaraja.

Pengurus Tempat Ibadah Tridharma. 2013. Tempat Ibadah Tridharma. Singaraja.

Sujaya, I M. 2014. Inilah Sekolah Pertama di Bali yang Turut Andil dalam Kelahiran Soekarno. Denpasar. http://www.balisaja.com/2014/05/inilah-sekolah-pertama-di-bali.html (Diunduh: 11 Januari 2016).

Susanti. 2014. Potensi Masjid Nur Singaraja, Bali Sebagai Sumber Belajar Sejarah Kebudayaan di SMA. Undiksha, Singaraja.

UPTD, Gedong Kirtya. 2013. Sejarah Gedung Kirtya Singaraja. Singaraja.

\section{Ucapan Terima Kasih}

Kepada I Made Sukewijaya, S.P., M.Sc dan Lury Sevita Yusiana, S.P., M.Si selaku dosen pembimbing skripsi yang telah memberikan bimbingan kepada penulis hingga manuskrip ini dapat diselesaikan. 